\title{
Impacts of PM2.5 on respiratory system among traffic policemen
}

\begin{abstract}
Background: Malaysian traffic policemen are constantly exposed to unhealthy air in the outdoor environment, which results in various health problems. This study investigates the relationship of the personal exposure level to PM2.5 and lung functions in traffic policemen in Kuala Lumpur and Johor Bahru. Methods: A pulmonary function test using a spirometer was carried out to measure the lung function of the traffic policemen. The personal exposure level to PM2.5 was measured using a pump with a PVC filter and 5.0 $\mu \mathrm{m}$ pore size. A questionnaire requesting the background data, such as age, height, and weight, was also used for testing lung function abnormalities. Results: The PM2.5 personal exposure level was found to be significantly related to lung function (predicted FEV1 and predicted FVC) at p-value $<0.05$. Conclusions: Traffic policemen are mainly exposed to physical hazards from traffic pollutants emitted by vehicles, such as fine particles and particulate matter. The findings of this study indicate that there is a trend of lung function deterioration among traffic policemen. These baseline data can serve as a reference for the top management of traffic police to aid in the development of occupational safety and health guidelines for police officers, as the traffic police are not covered by the Occupational Safety and Health Act (OSHA, Act 514 1994).
\end{abstract}

Keyword: Spirometer; Lung function; Occupational health; Respiratory health 